\title{
Mesenteric fat-control site for bacterial translocation in colitis?
}

\author{
A Batra ${ }^{1}$, MM Heimesaat $^{2}$, S Bereswill ${ }^{2}$, A Fischer ${ }^{2}$, R Glauben $^{1}$, D Kunkel ${ }^{3}$, A Scheffold ${ }^{4}$, U Erben ${ }^{1}$, \\ A Kühl ${ }^{5}$, C Loddenkemper ${ }^{5}$, H-A Lehr ${ }^{6}$, M Schumann $^{1}$, J-D Schulzke $^{1}$, M Zeitz $^{1}$ and B Siegmund ${ }^{1}$
}

In Crohn's disease bacteria could be detected in the adjacent mesenteric fat characterized by hypertrophy of unknown function. This study aimed to define effector responses of this compartment induced by bacterial translocation during intestinal inflammation. Dextran sulfate sodium-induced colitis served as a model of intestinal inflammation. Translocation of peptides and bacteria into mesenteric fat was evaluated. Innate functions of mesenteric fat and epithelium were characterized at whole tissue, cellular, and effector molecule levels. Orally applied peptides translocated in healthy wild-type (WT) mice. Bacterial translocation was not detected in healthy and acute but increased in chronic colitis. Mesenteric fat from colitic mice released elevated levels of cytokines and was infiltrated by immune cells. In MyD88 /- mice bacterial translocation occurred in health and increased in colitis. The exaggerated cytokine production in mesenteric fat accompanying colonic inflammation in WT mice was less distinct in MyD88-/- mice. In vitro studies revealed that fat not only increases cytokine production following contact with bacterial products, but also that preadipocytes are potent phagocytes. Colonic inflammation is accompanied by massive cytokine production and immune cell infiltration in adjacent adipose tissue. These effects can be considered as protective mechanisms of the mesenteric fat in the defense of bacterial translocation.

\section{INTRODUCTION}

In Crohn's disease a hypertrophy of the mesenteric fat adjacent to the inflamed intestinal segments represents a pathognomonic finding. Although in this tissue a decreased adipocyte size is accompanied by an increase in number and changes in the local pattern of soluble mediators, its biological significance has not been revealed yet. ${ }^{1}$ In addition, bacterial translocation to the mesenteric adipose tissue is increased. ${ }^{2,3}$ We aimed to understand whether intestinal inflammation per se leads to translocation of live bacteria into mesenteric fat, and to dissect mesenteric fat tissue functions in intestinal inflammation and its possible role in the control of bacterial translocation.

Work from the last decade indicates that adipose tissue can regulate immune responses and suggests a link between the endocrine and the immune system. ${ }^{4}$ Adipose tissue has been identified as a potent producer not only of adipokines such as leptin but also of cytokines and chemokines, such as interleukin- 6
(IL-6) and the monocyte chemoattractant protein-1 (MCP-1). ${ }^{4-6}$ Leptin, increased in the mesenteric fat of Crohn's disease patients, is involved in T-cell polarization and reactivity of the innate immune system. ${ }^{4}$ Pleiotropic IL-6 induces C-reactive protein, proliferation, and expression of adhesion molecules on a multitude of target cell types. ${ }^{7}$ High IL-6 serum concentrations in obesity are derived from visceral adipose tissue. ${ }^{8}$ The chemokine MCP-1, the murine equivalent to the human $\mathrm{C}-\mathrm{C}$ motif ligand 2 mediates monocyte migration. ${ }^{9}$ Interestingly, production of these factors is increased in the mesenteric fat of Crohn's disease patients. ${ }^{10}$

Production of these mediators can be induced by bacterial products, resulting in Toll-like receptor (TLR)-dependent stimulation of adipocytes and preadipocytes. TLR4 was the first innate receptor shown to be expressed on the preadipocyte cell line 3T3L1. ${ }^{11}$ Own studies with primary preadipocytes and adipocytes from mesenteric fat tissue indicated the expression

\footnotetext{
${ }^{1}$ Medical department I, Charité-Universitätsmedizin Berlin, Campus Benjamin Franklin, Berlin, Germany. ${ }^{2}$ Institute of Microbiology and Hygiene, CharitéUniversitätsmedizin Berlin; Campus Benjamin Franklin, Berlin, Germany. ${ }^{3}$ Berlin-Brandenburg Center for Regenerative Therapies; Charité-Universitätsmedizin Berlin, Campus Virchow Klinikum; Berlin, Germany. ${ }^{4}$ Miltenyi Biotec, Bergisch Gladbach, Germany. ${ }^{5}$ nstitute of Pathology/RCIS, Charité-Universitätsmedizin Berlin, Campus Benjamin Franklin, Berlin, Germany. ${ }^{6}$ Institute of Pathology, University Hospital of Lausanne, Lausanne, Switzerland. Correspondence: B Siegmund (britta.siegmund@charite.de) 
of functional TLR1-TLR9 as well as of the intracellular pattern recognition receptors nucleotide oligomerization domain 1 and 2 and altered production of cytokines following their specific stimulation. ${ }^{12,13}$ This suggests that bacteria invading the mesenteric adipose tissue in the course of colitis could affect the local release of mediators by adipocytes and preadipocytes. Interestingly, mutations in the numerous genes critical for the innate immune response, for example nucleotide oligomerization domain 2 and ATG16L1, have been identified to confer susceptibility to Crohn's disease. ${ }^{14}$ Hence, the increased presence of live bacteria could be linked to defects in local defense mechanisms.

To define the immunological function of the mesenteric fat tissue adjacent to the inflamed intestine murine models of acute and chronic intestinal inflammation were applied and the colonic bacterial load, the bacterial translocation as well as the local response to bacterial antigens were evaluated. To understand the role of the innate immune system in the control of bacterial translocation, mice deficient for MyD88, an adaptor protein with a key role in TLR-dependent signaling, were included. ${ }^{15}$

\section{RESULTS}

\section{Translocation of peptides and bacteria}

To evaluate small peptide translocation from the gut and their presentation particularly in the mesenteric fat tissue, fluorescent ovalbumin peptide (FOva) was administered orally to wild-type (WT) mice. The relevance of intestinal inflammation in this process was delineated by comparing healthy WT mice to mice suffering from dextran sulfate sodium (DSS) colitis. FOva translocation and consecutive major histocompatibility complex (MHC)II-dependent presentation as determined by $\mathrm{FOva}^{+} \mathrm{MHCII}^{+}$cells after $3 \mathrm{~h}$ was frequent even in healthy mice and not altered by intestinal inflammation (Figure 1). Remarkably, percentages of $\mathrm{FOva}^{+} \mathrm{MHCII}^{+}$cells resulting from peptide translocation were as common in the mesenteric fat as in mesenteric lymph nodes, peyer's patches, and the spleen, suggesting that ingested peptides typically reach mesenteric adipose tissue.

Beside nutritional components, the intestine harbors a multitude of colonizing bacteria with colonic bacterial flora being altered in intestinal inflammation. ${ }^{16}$ To understand if alterations of the gut flora are linked to the incidence of bacterial translocation, we induced colitis and studied both, gut flora dynamics as well as bacterial translocation in the course of intestinal inflammation in acute and chronic colitis with increasing periods of treatment $(3,4$, or 5 cycles of DSS application in the drinking water, Figure 2).

Bacterial translocation did not occur in healthy mice and was negligible in acute DSS colitis (Table 1). However, chronic colitis as induced by three, four, or five cycles of DSS facilitated bacterial translocation. Mesenteric fat tissue, mesenteric lymph node, and liver harbored the highest percentages of samples with live bacteria (up to $40 \%$ ). Interestingly, bacterial translocation as present after three cycles of DSS treatment did not further increase with prolonged chronic colitis (Figure 3a). a
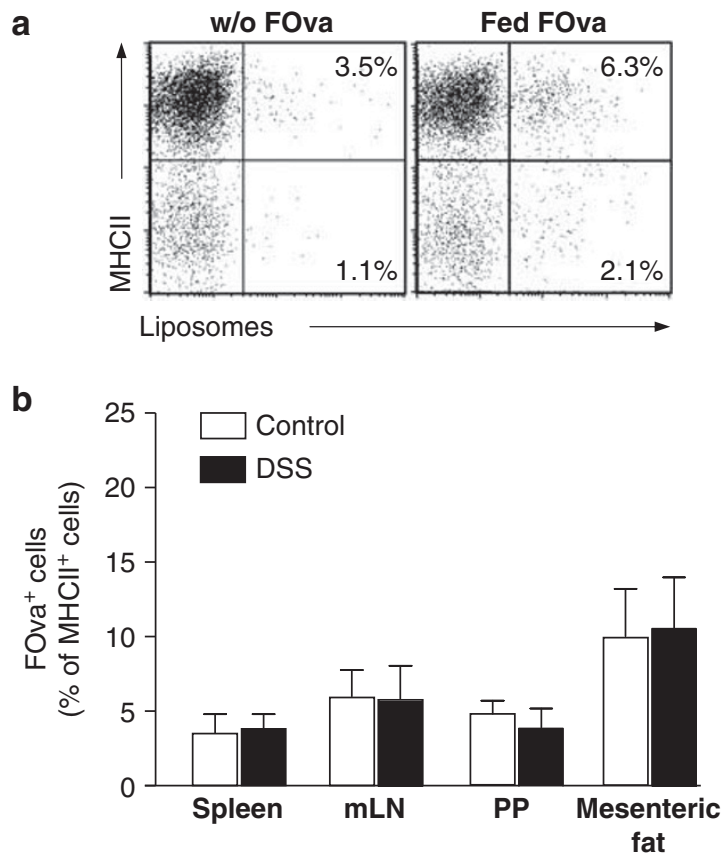

Figure 1 Translocation of small peptide antigen. FOva was administered orally (1 mg per mouse) to WT mice. After $180 \mathrm{~min}$, cells from different organs were isolated and $\mathrm{MHCll}$-bound FOva was assessed by flow cytometry. (a) Representative FOva-specific staining of mesenteric fat cells of healthy mice with or without feeding of FOva. (b) In-vivo binding of FOva to $\mathrm{MHCll}^{+}$cells of organs as indicated from healthy mice or mice with acute DSS colitis was determined. Mean values \pm S.e.m. of eight mice per group. DSS, dextran sulfate sodium; FOva, fluorescent ovalbumin peptide; MHCII, major histocompatibility complex II; WT, wild type.

The total luminal bacterial load was significantly decreased after three cycles of DSS and increased back to baseline after five cycles. When focusing on the composition of bacterial species, Escherichia coli and Bacteroides/Prevotella spp. increased in DSS-treated mice, with a maximum after four and five cycles, respectively. In contrast, Lactobacillus and Gram-positive cocci decreased, and only for lactobacilli a partial recovery could be observed (Figure 3b).

Taken together, whereas translocation of small peptides is independent from colonic inflammation, chronic but not acute colitis favors bacterial translocation, but this is independent from the colonic bacterial load.

\section{Defining the role of the mesenteric fat tissue during intestinal inflammation}

Assuming that local adipose tissue participates in intestinal inflammation, we first analyzed the immune cell composition in the mesenteric fat as compared with subcutaneous fat. In subcutaneous fat of controls as well as colitic mice immune cells were virtually absent (Figure 4a). In the mesenteric fat from colitic mice an increase of both $\mathrm{CD}^{+} \mathrm{T}$ cells and $\mathrm{F} 4 / 80^{+}$ macrophages was present (Figure $4 \mathrm{~b}$ ), leading to the overall rise in local immune cells (Figure 4c). To further characterize the immune cell subpopulations within the mesenteric fat tissue, cellular infiltrates of healthy and diseased mice were 

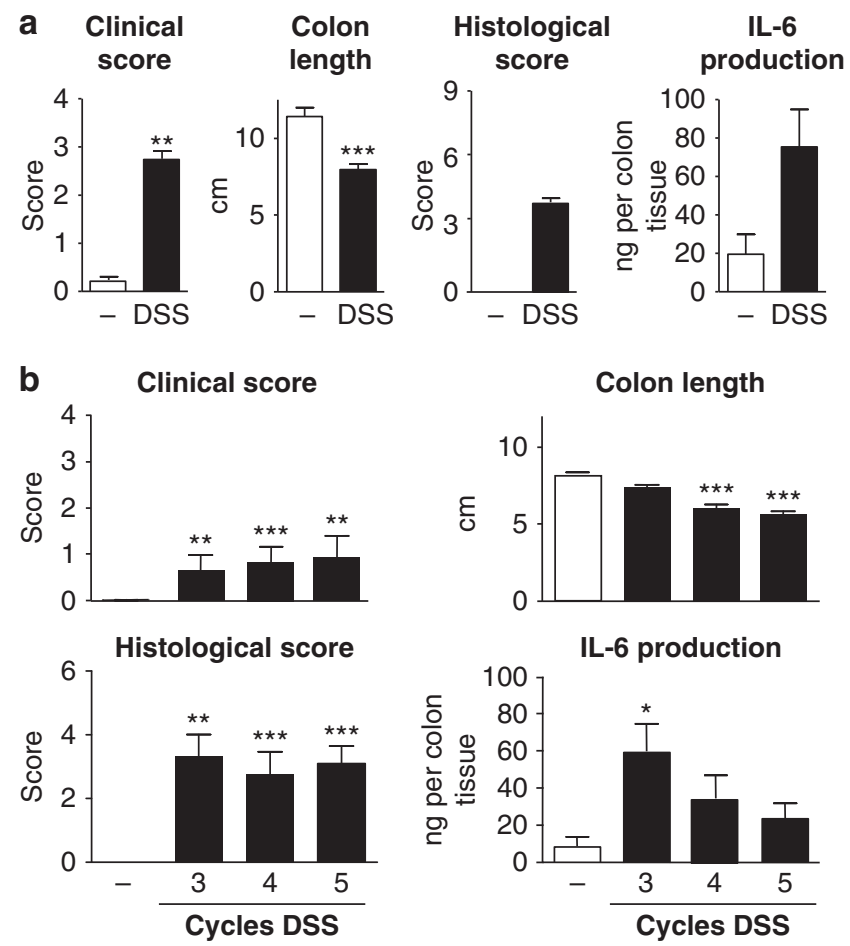

Figure 2 Clinical parameters in DSS colitis. Acute (a) or chronic (b) colitis were induced in WT mice by either one cycle or by repeated cycles of DSS, respectively. To confirm colonic inflammation, the clinical and histological score, colon length as well as production of IL- 6 by the excised colon were evaluated at various time points. Bars represent mean values \pm s.e.m. of 10 mice per time point and group. ${ }^{*} P<0.05$; ${ }^{* \star} P<0.01$; and ${ }^{* * *} P<0.005$ by Kruskal-Wallis with Dunn's post test. DSS, dextran sulfate sodium; WT, wild type.

Table 1 Bacterial translocation in acute DSS colitis

\begin{tabular}{|c|c|c|}
\hline \multirow[t]{2}{*}{ Tissue } & \multicolumn{2}{|c|}{$\begin{array}{c}\text { Samples with live bacteria (\% of all } \\
\text { samples) }\end{array}$} \\
\hline & Controls $(n=14)$ & DSS colitis $(n=14)$ \\
\hline Blood & 0 & 0 \\
\hline MLN & 0 & 14 \\
\hline Spleen & 0 & 10 \\
\hline Mesenteric fat & 0 & 14 \\
\hline
\end{tabular}

Abbreviations: DSS, dextran sulfate sodium; WT, wild type.

Acute DSS colitis was established in WT mice and live bacteria were evaluated by cultural analysis of the respective samples from these mice and from healthy controls. Given for each tissue are the percentages of samples tested that harbored living bacteria.

compared by flow cytometry (Table 2). Remarkably, no changes in the overall composition of $\mathrm{T}$ vs. B cells or macrophages were observed by flow cytometry, with exception of the frequency of Gr- $1^{+}$macrophages that increased significantly during DSS colitis. Immunohistochemical staining of samples of colon and mesenteric fat for macrophage subsets using inducible nitric oxide synthase and $\mathrm{Ym}-1$ to distinguish between macrophages polarized to the M1 and M2 type, respectively, revealed an overall increase in macrophages including M2 cells in mesenteric fat in colitis (Supplementary Figure 1 online). Although the cellular composition of local immune cell subsets was hardly
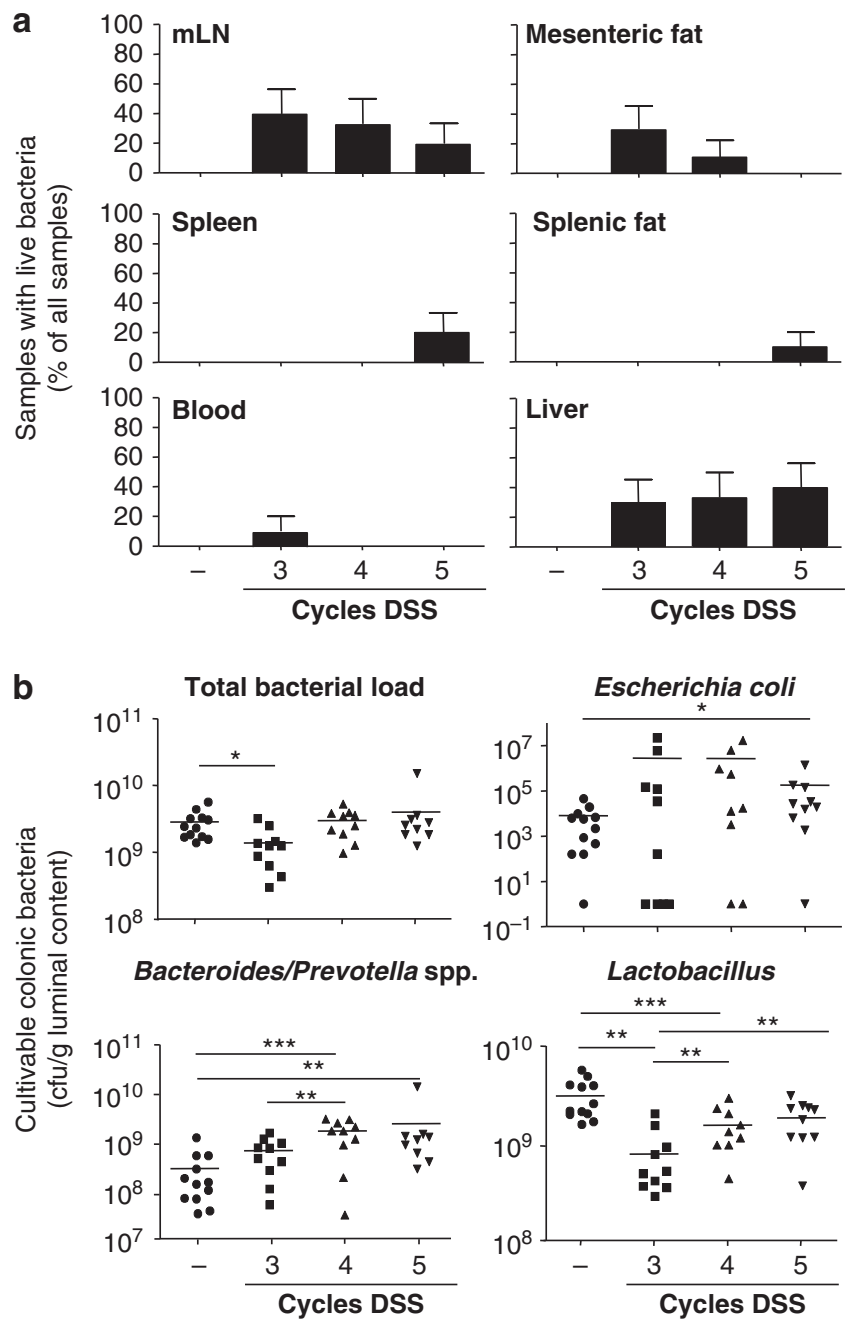

Figure 3 Colonic bacteria and translocation of bacteria in chronic DSS colitis. Chronic colitis was established in WT mice by repeated DSS cycles. Live bacteria were evaluated by cultural analysis of the respective samples from these mice and from healthy controls. (a) For each group the percentages of samples harboring live bacteria were calculated. Mean values \pm s.e.m. of 7-12 mice per group. (b) Amounts of total bacteria and defined bacterial subgroups were determined from colonic content. Median values of $7-12$ mice per group. ${ }^{*} P<0.05$. ${ }^{* \star} P<0.01$, and ${ }^{* \star \star} P<0.005$ by Mann-Whitney U-test. DSS, dextran sulfate sodium; WT, wild type.

affected by disease, the increase in infiltrating cells was striking (Figures $\mathbf{4 b}$ and $\mathbf{c}$ ).

Earlier work identified functional TLR on adipocytes as well as preadipocytes and altered mediator production following stimulation with bacterial products. ${ }^{12}$ As altered cytokine production could consequently be an indirect indicator of bacterial antigens, we assessed the local cytokine milieu in mesenteric adipose tissue from colitic and healthy WT mice. To gain information about the levels of responsiveness in these tissues, samples were additionally stimulated with lipopolysaccharide (LPS) in vitro.

In colitis, MCP-1 and IL-10 production were significantly increased in the mesenteric, but not in the subcutaneous fat (Figure 5a). LPS stimulation in vitro further upregulated the 


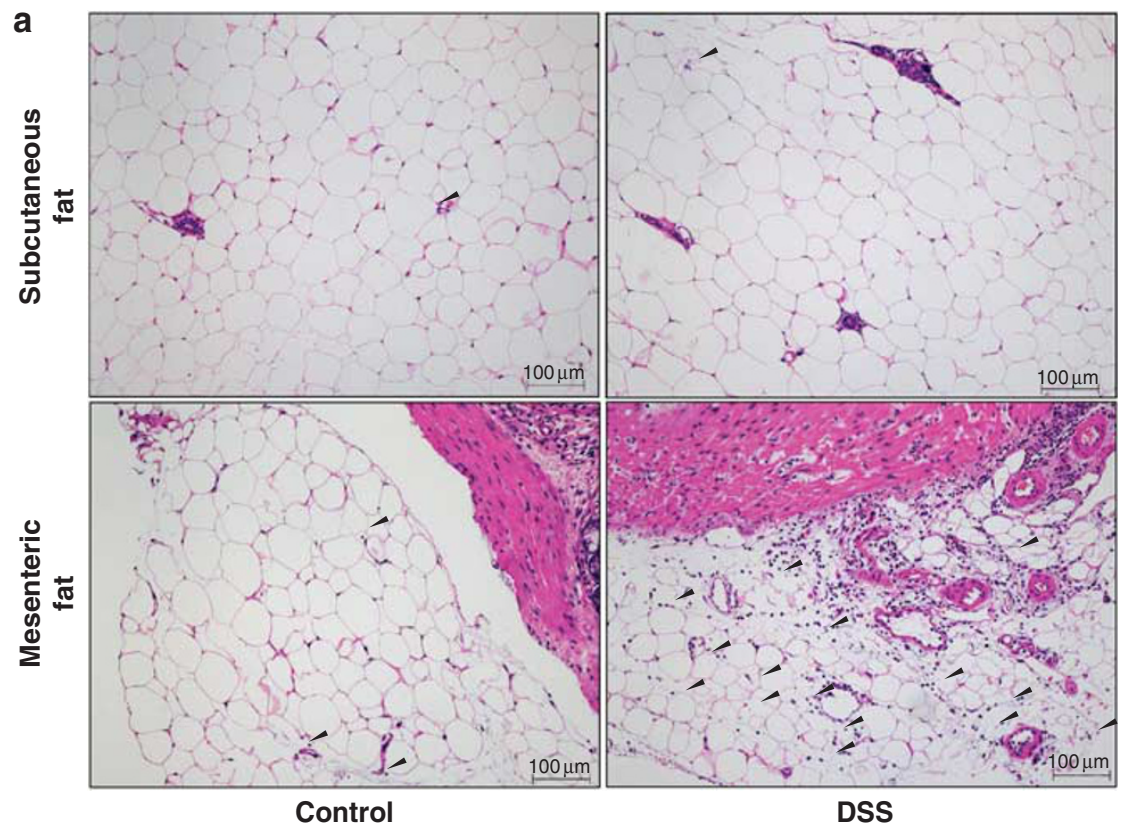

b

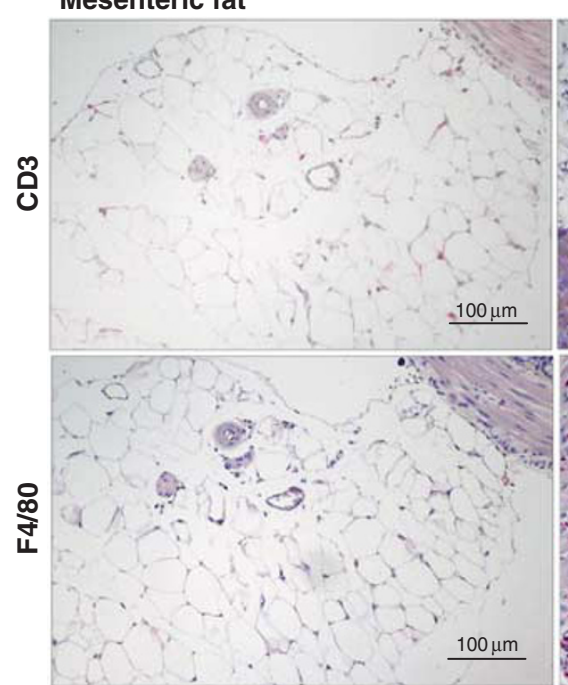

Control

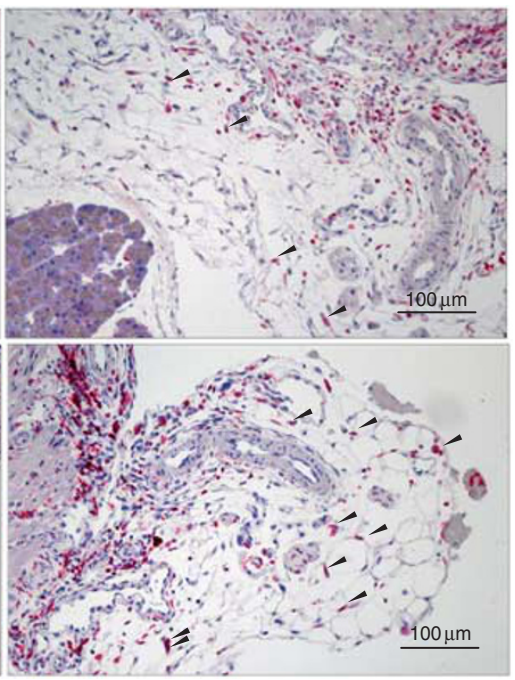

DSS

C

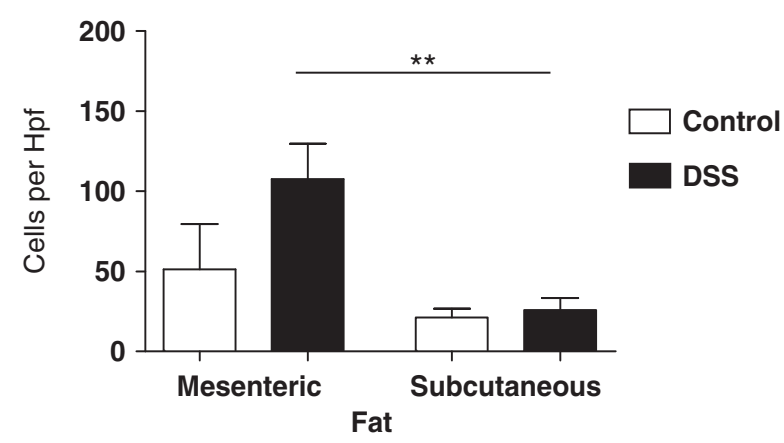

Figure 4 Infiltrating immune cells in adipose tissue. (a) Fat from healthy WT mice and mice with DSS colitis were stained with hemaotoxylin for the presence of infiltrating cells. (b) Samples of mesenteric fat were stained for the presence of $\mathrm{CD}^{+} \mathrm{T}$ cells or of F $4 / 80^{+}$macrophages. Representative samples for all groups at 100 -fold magnification are shown. Arrowheads point to positive cells in the fat tissue. (c) Comparative cell counts of immune cells per high-power field (hpf) in mesenteric fat and subcutaneous fat of healthy and colitic mice. ${ }^{\star \star} P<0.01$ by Student's $t$-test. DSS, dextran sulfate sodium; WT, wild type. 
Table 2 Immune cells infiltrating adipose tissues in chronic DSS colitis

\begin{tabular}{|c|c|c|c|c|c|c|}
\hline Ratio: \% B and T cells & $0.6 \pm 0.1$ & $0.6 \pm 0.1$ & $0.4 \pm 0.1$ & $0.3 \pm 0.1$ & $2.5 \pm 0.2$ & $2.3 \pm 0.2$ \\
\hline Ratio: \%T cells and \%M $\varnothing$ & $3.8 \pm 1.1$ & $4.3 \pm 1.2$ & $3.7 \pm 2.2$ & $0.8 \pm 0.2$ & $19.2 \pm 2.4$ & $12.4 \pm 2.2$ \\
\hline CD69 ${ }^{+}$CD4 ${ }^{+}$T cells $(\%)$ & $23.8 \pm 3.2$ & $19.9 \pm 2.0$ & $21.5 \pm 2.7$ & $26.0 \pm 2.6$ & $9.1 \pm 1.7$ & $7.1 \pm 0.9$ \\
\hline $\mathrm{MHCll}+$ cells (\%) & $28.5 \pm 3.6$ & $32.7 \pm 2.4$ & $18.4 \pm 1.6$ & $17.1 \pm 1.1$ & $65.4 \pm 1.4$ & $63.4 \pm 1.3$ \\
\hline
\end{tabular}

Abbreviations: DSS, dextran sulfate sodium; MHC, major histocompatibility complex; WT, wild type.

Mononuclear cells were isolated from mesenteric or subcutaneous adipose tissue and from spleens of mice with or without DSS colitis. Frequencies of CD19+ $\mathrm{B}$ cells, subsets of $\mathrm{CD}^{+}$T cells, and of MOMA-2+ macrophages as well as CD4-, CD69-, MHCll-, and Gr-1-positive cells were assessed by flow cytometry. Data represent mean values \pm s.e.m. of six independent experiments.

${ }^{*} P<0.05$ compared with the control group without DSS colitis.

expression of tumor necrosis factor- $\alpha$, IL-10, MCP-1, and IL- 6 significantly in most cultures. These LPS-induced cytokine profiles reflected those spontaneously released ex vivo from mesenteric fat of colitic mice. In cultures from subcutaneous fat all mediators increased following LPS stimulation accordingly, but unlike in samples of mesenteric fat, cytokine production in ex vivo isolated samples was not significantly different in tissues from controls and DSS-exposed animals. These observations support that in colitis cytokine production in the mesenteric fat is increased, which might be linked to translocation of bacterial products such as LPS to this site.

Earlier reports have documented that the 3T3L1 preadipocyte cell line is capable of phagocytosis. ${ }^{17}$ To understand whether mesenteric murine preadipocytes are efficient in the uptake of bacterial products as well, the phagocytosis of different antigens by preadipocytes initially isolated from the mesenteric fat of mice was assessed, using bone marrow-derived dendritic cells as well as bone marrow-derived macrophages as a reference for professional phagocytes. As shown in Figures $\mathbf{5 b}$ and $\mathbf{c}$ preadipocytes were competent in the phagocytosis of a broad range of antigens. Thus, phagocytosis represents one defense mechanism that bacteria have to face when they translocalize into mesenteric fat. However, unlike macrophages preadipocytes do not express MHCII on their surface (Supplementary Figure 2 online), indicating that preadipocytes do not function as antigenpresenting cells (APCs) in the fat tissue.

\section{Innate immune system as critical regulator of bacterial translocation}

Our results indicated that live bacteria are present in $<20 \%$ of mice with colonic inflammation. To study the impact of innate immunity on bacterial translocation, we subjected MyD88 ${ }^{-/-}$ mice to chronic colitis. As described previously, ${ }^{18,19} \mathrm{MyD}^{-/-}$ mice were more susceptible to DSS, indicated by a significantly increased mortality over a 30-day experimental time course (Figure 6a). Remarkably, even in healthy MyD88 ${ }^{-/-}$mice bacteria translocated to all tissues analyzed (Figure $\mathbf{6 b}$ ). The incidence was comparable to WT mice suffering from chronic DSS colitis and was about 2 -fold increased in MyD88 ${ }^{-1-}$ mice with intestinal inflammation.

To understand underlying mechanisms we compared the functionality of the epithelial barrier of $\mathrm{MyD} 88^{-1-}$ mice to WT littermates (Figures $7 \mathbf{a}$ and $\mathbf{b}$ ). The transmural and epithelial electrical resistance, as well as the membrane permeability for mannitol, were decreased in colon samples of MyD88 ${ }^{-/-}$ mice (Figure 7c). However, when normalized for the increased surface area of the colon in MyD88 ${ }^{-1-}$ mice where we noticed increased crypt height and number (Figure 7d), all differences in these parameters became negligible, suggesting that increased bacterial translocation in MyD88 $8^{-/-}$mice is not due to augmented epithelial permeability.

Next, tissue-specific chemokine and cytokine responses were evaluated in WT and MyD88 $8^{-/-}$mice suffering from chronic DSS colitis. The production of tumor necrosis factor- $\alpha$, MCP- 1 , and IL-6 was significantly upregulated in colon supernatants from WT mice suffering from chronic DSS colitis. Although baseline levels of these molecules were lower in colon supernatants of MyD88 $8^{-1-}$ mice, all mediators tested including IL-10 were upregulated in the colon cultures of diseased MyD88 ${ }^{-1-}$ mice as well even though this did not reach significance (Figure 8a). In the mesenteric fat production of tumor necrosis factor$\alpha$ and IL-10 was low in healthy mice but increased in tissue from colitic mice. Interestingly, MCP-1 was upregulated in the mesenteric fat tissue upon disease in WT mice and was significantly higher than in samples from colitic MyD88 ${ }^{-/-}$mice where no such increase occurred. In addition, the IL- 6 release of the mesenteric fat was independent of colitis but higher in WT than in MyD88 ${ }^{-1-}$ mice (Figure 8b). Additional 

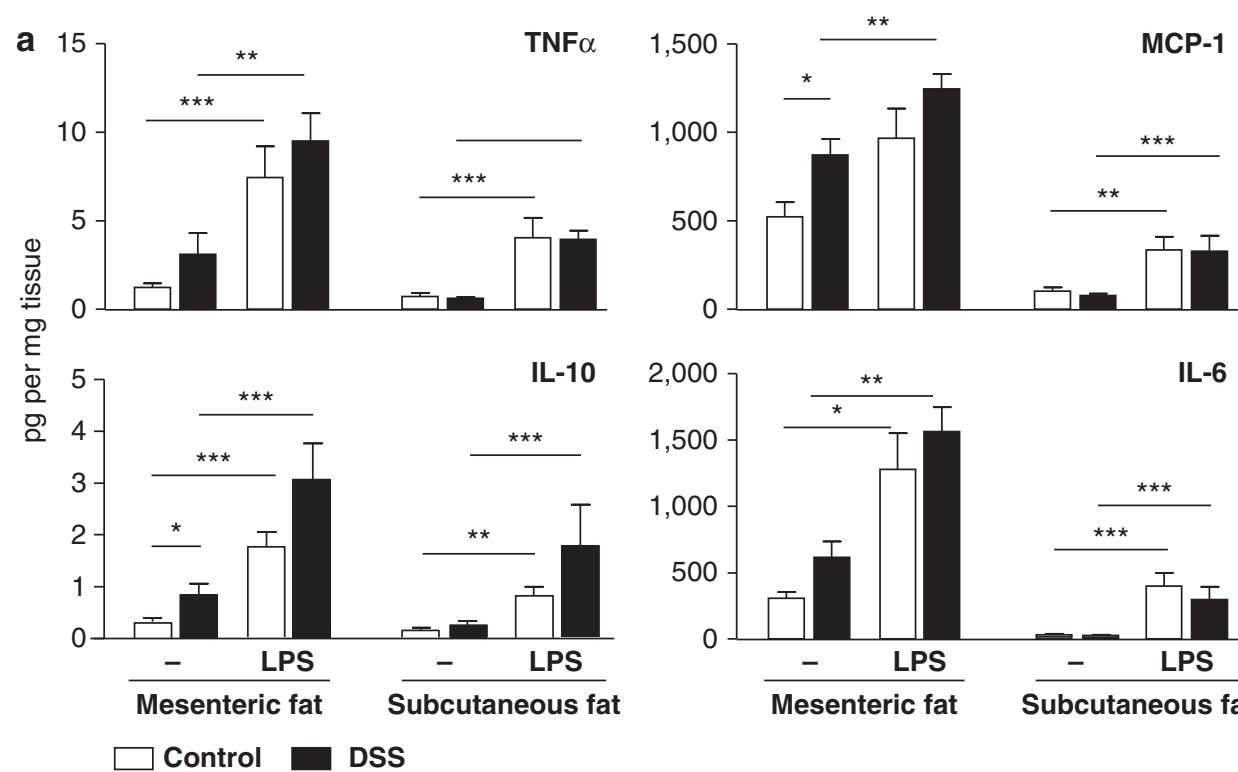

b Control

Ovalbumin

Latex beads

S. aureus opsonized
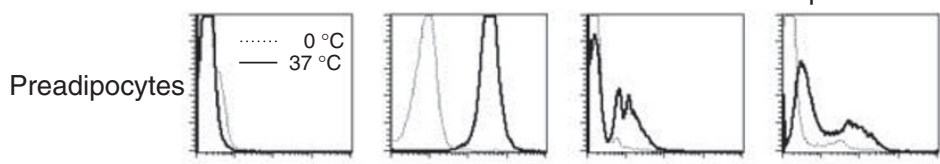

S. aureus
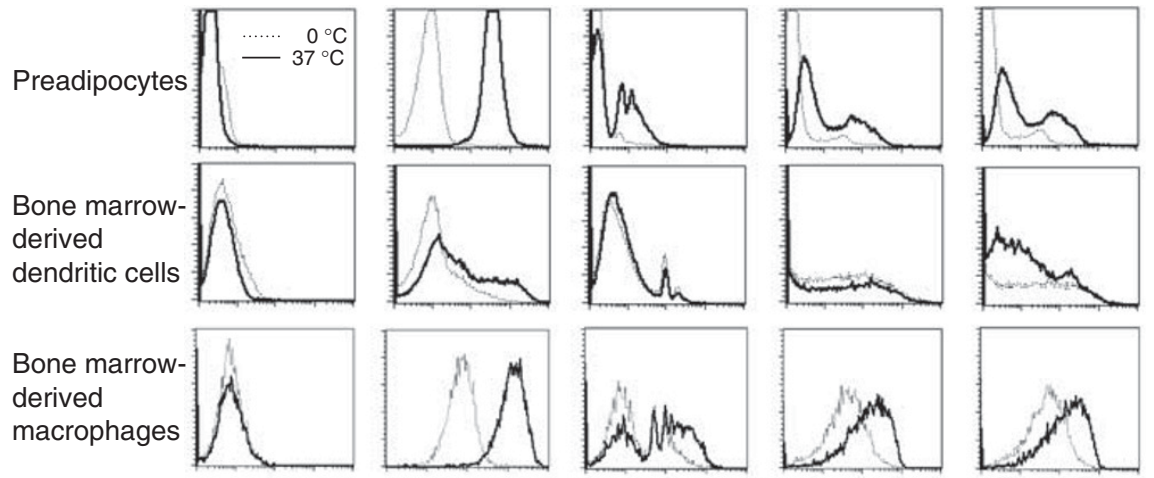

Phagocytosis

C

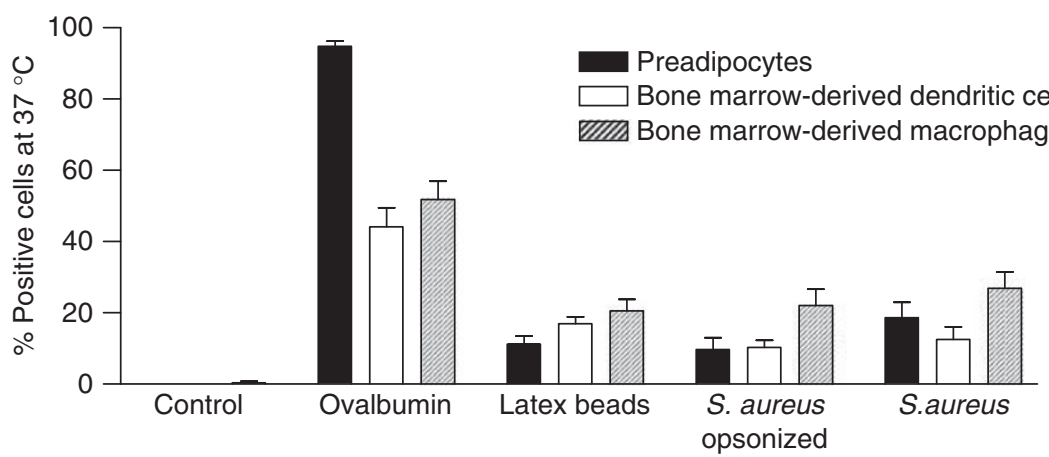

Figure 5 Phagocytosis by preadipocytes and cytokine production by whole adipose tissue of WT mice. (a) Whole adipose tissue samples from healthy mice or mice with acute DSS colitis were incubated in vitro with $1 \mu \mathrm{g} \mathrm{ml}^{-1} \mathrm{LPS}$ for $20 \mathrm{~h}$. Cytokine responses were assessed from the supernatants by CBA. Mean values \pm s.e.m. of 10 independent samples. (b) Preadipocytes ,bone marrow-derived dendritic cells, and macrophages were incubated with fluorescent antigens at $0^{\circ} \mathrm{C}$ (upper panel; dotted line) or $37^{\circ} \mathrm{C}$ (upper panel; bold line) to discriminate surface binding from antigen uptake. (c) Mean values obtained at $0^{\circ} \mathrm{C}$ were subtracted from the values at $37^{\circ} \mathrm{C}$ to quantify the percentage of phagocyting cells. Mean \pm s.e.m. of six to eight independent experiments (lower panel). ${ }^{*} P<0.05$, ${ }^{\star \star} P<0.01$, and ${ }^{\star * \star} P<0.005$ by Student's $t$-test. CBA, Cytometric Bead Array; DSS, dextran sulfate sodium; LPS, lipopolysaccharide; WT, wild type.

in vitro experiments revealed that LPS-induced IL-6 production in preadipocytes disappears if LPS is withdrawn. The responsiveness of preadipocytes persists even if they are stimulated repeatedly (Supplementary Figure 3 online).
Leptin has been identified to aggravate intestinal inflammation. ${ }^{20-22}$ Its production was significantly upregulated in supernatants of tissues from WT animals suffering from chronic DSS colitis, an effect that was evident in both, mesenteric and 

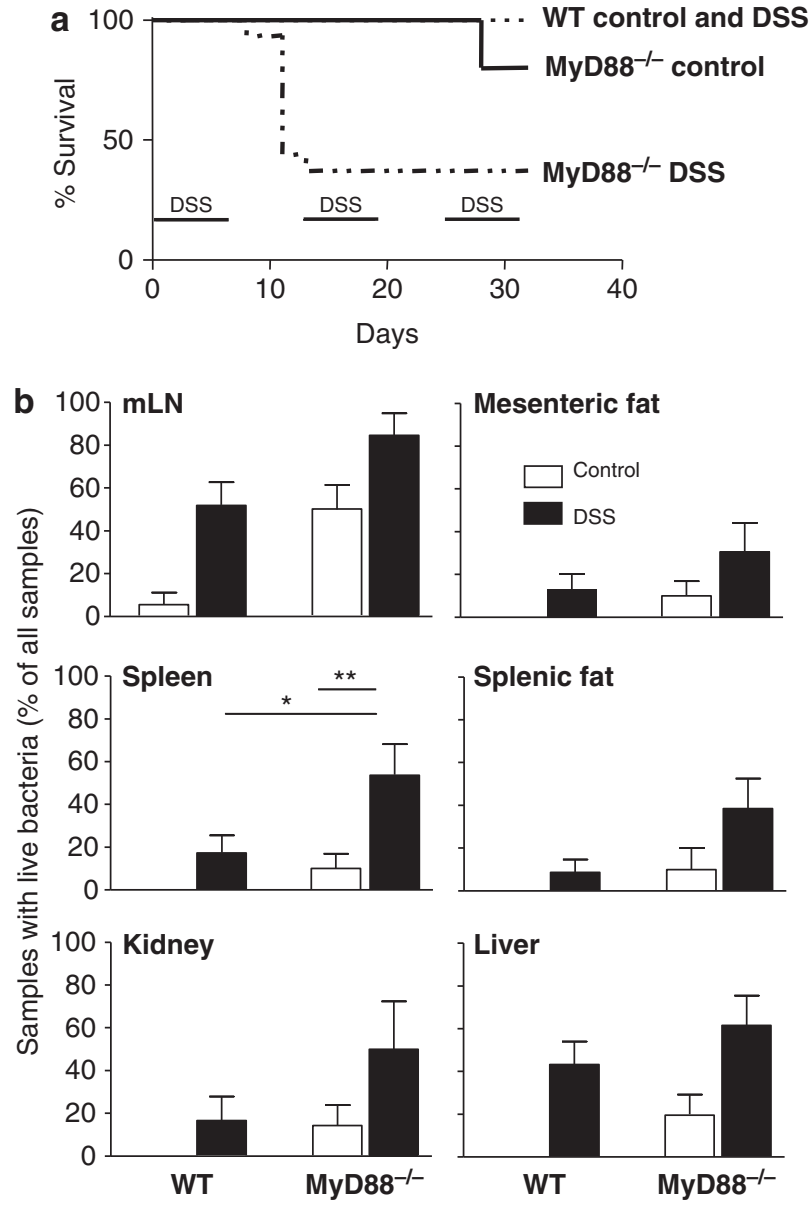

Figure 6 MyD88-dependent regulation of bacterial translocation. Chronic DSS colitis was induced in WT and MyD88 ${ }^{-/-}$mice. (a) Survival of WT and MyD88 ${ }^{-/}$mice during DSS colitis compared with healthy controls. (b) Total bacteria cultivable from organs as indicated were analyzed. Percentages of samples with live bacteria were calculated for control mice and mice that received three cycles of DSS. Mean values \pm s.e.m. of $18 \mathrm{WT}$ and $23 \mathrm{MyD} 88^{-/-}$mice controls as well as $23 \mathrm{WT}$ and $13 \mathrm{MyD} 88^{-/-}$mice with chronic colitis. ${ }^{*} P<0.05$, ${ }^{* \star} P<0.01$ by KruskalWallis with Dunn's post test. DSS, dextran sulfate sodium; WT, wild type.

subcutaneous fat. However, local leptin production was not affected by chronic colitis in the mesenteric fat of MyD88 ${ }^{-/-}$ mice (Figure 8c).

\section{DISCUSSION}

Bacterial translocation during chronic intestinal inflammation, in particular in Crohn's disease, is well accepted. Considering that in these patients the mesenteric fat is hypertrophied and wraps around the inflamed intestinal segments, this might be of particular interest, as the function of this creeping fat has not been elucidated at this point. Here, we aimed to characterize the role of mesenteric adipose tissue in the control of bacterial translocation. Our data indicate that mesenteric adipose tissue is involved in intestinal inflammation with regard to local cytokine release and cellular composition. Even though live bacteria were rarely detected, colonic inflammation was always accompanied by immune cell infiltration and increased local cytokine production in the adjacent mesenteric fat in WT mice. As excised adipose tissue exerts similar cytokine responses when stimulated with the TLR4 ligand LPS, one can assume that, bacterial products invade adipose tissue in the course of colitis. Additional in vitro studies indicated a persisting LPS responsiveness of preadipocytes even after repetitive stimulation. These data suggest that the enhanced cytokine production in the mesenteric fat of mice with experimental colitis is an indicator for the presence of bacterial antigens. In summary, the local cytokine responses, as well as the ability of preadipocytes to function as phagocytes, are sufficient to control bacterial translocation in acute colitis. However, only chronic colitis favored bacterial translocation in WT mice. This might be linked to an impaired innate receptor response in chronic inflammation, since in $\mathrm{MyD} 88^{-/-}$mice bacterial translocation into the mesenteric fat occurs even in health and is further enhanced in intestinal inflammation.

Translocation of oligopeptides from the intestine into the body occurs naturally. ${ }^{23}$ To characterize whether translocation of nutritional antigens into the mesenteric fat is a common incident, presentation of FOva by $\mathrm{MHCII}^{+}$cells was assessed by a highly sensitive method, allowing to detect $<100$ peptide molecules per cell-the physiological threshold for the activation of T cells. ${ }^{24,25}$ Remarkably, peptide translocation into the mesenteric fat tissue was seen in health and not altered by intestinal inflammation. Since the ileum not only takes up single amino acids and dipeptides but also larger peptides, ${ }^{23}$ the main proportion of the peptide used might have been absorbed in the ileum and thus the rate of translocation was not affected by colonic inflammation. In contrast to peptides, bacterial translocation to the mesenteric fat and other organs increased significantly in chronic colitis. Importantly, this did not reflect a simple increase in colonic bacterial load as the rate of bacterial translocation did not mirror the changes in the total amount of colonic bacteria that accompanied colitis. Why is bacterial translocation relevant to Crohn's disease? Early data describe a loss of tolerance to the habitual intestinal flora in inflammatory bowel disease and suggest a critical role of the barrier. ${ }^{26,27}$ In addition, the epithelial barrier has been found dysfunctional in patients with Crohn's disease. ${ }^{28}$ Bacterial adhesion to and invasion of the mucus and wall of the intestinal tract is increased in colitis and in animal models of disease. ${ }^{29-33} \mathrm{~A}$ leaky barrier allowing for an enhanced translocation of bacteria leads to the central question of this work, the action and reaction of the adjacent mesenteric fat tissue.

Bacteria are present more frequently in the mesenteric fat tissue of Crohn's disease patients than in healthy controls. ${ }^{3}$ How does the fat tissue respond? A simple approach is to analyze infiltrating cell populations. In obese patients, it has been suggested that increased numbers of macrophages in their visceral fat contribute to chronic inflammation. ${ }^{34,35}$ In our colitis models, the main difference between healthy and diseased animals was the increase in immune cells present in the mesenteric fat with minor changes in the macrophage subset composition, suggesting a pro-inflammatory milieu similar to the before mentioned state of obesity.

Leading to the question what further lines of defense exist within the mesenteric adipose tissue? 
a
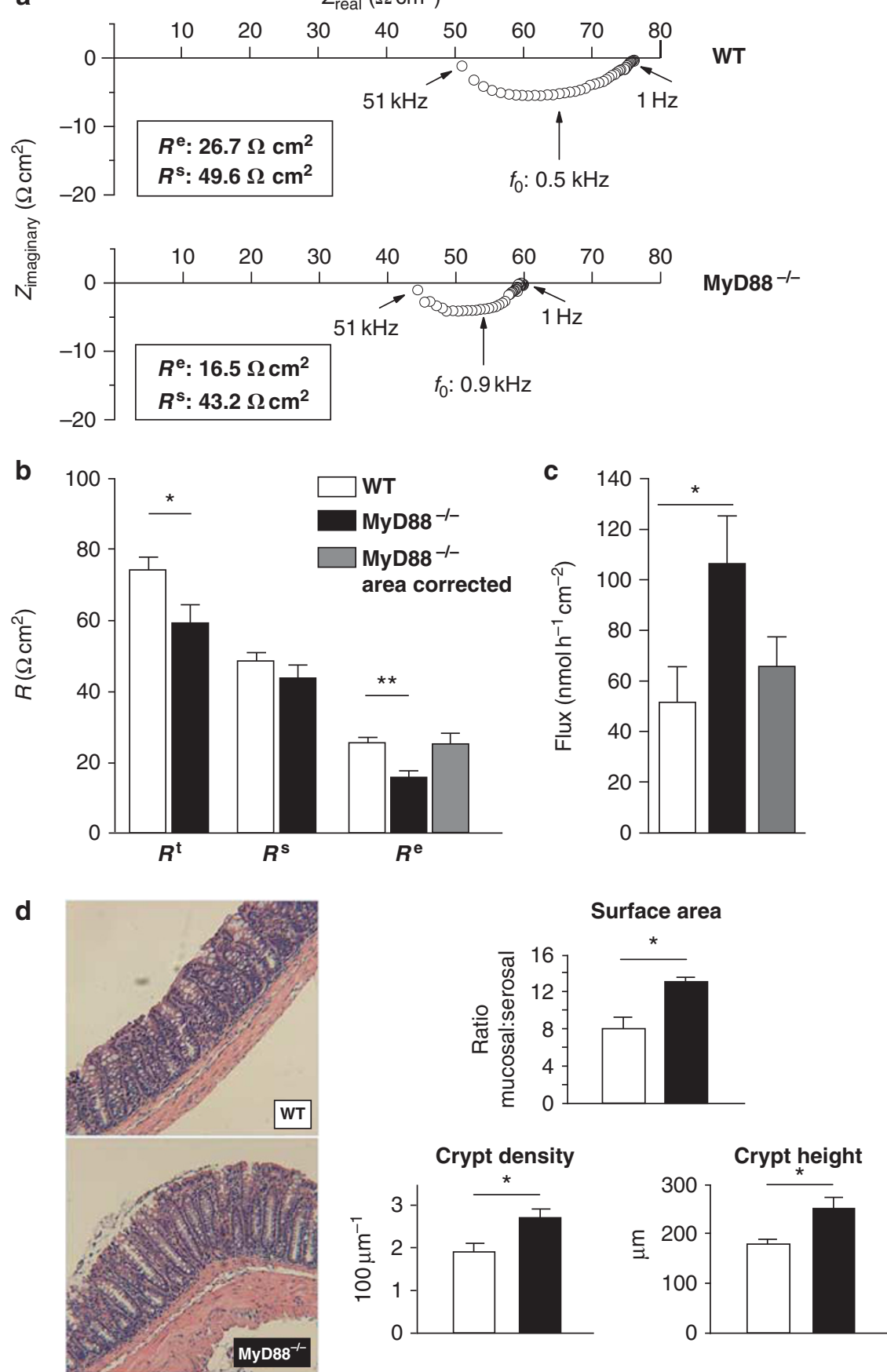

Figure 7 Analysis of epithelial barrier defects in MyD88 ${ }^{-/-}$mice. Colon specimens were mounted in Ussing chambers. (a) Representative Nyquist diagram of original impedance locus plots of the ohmic component $\left(Z_{\text {real }}\right)$ and the reactive component $\left(Z_{\text {imaginary }}\right)$ for WT and MyD88 ${ }^{-/-}$mice. (b) $R^{\mathrm{e}}, R^{\text {sub }}$, and $R^{\mathrm{t}}$ values of mouse colon as measured with impedance spectroscopy and (c) unidirectional mucosal-to-serosal fluxes of $\left[{ }^{3} \mathrm{H}\right] \mathrm{mannitol}$ with surface corrections for $R^{e}$ and mannitol fluxes. (d) Colonic sections stained with hematoxylin/eosin were analyzed to determine the crypt number and height as well as the ratio of the mucosal to serosal surface area. Mean values \pm s.e.m. of five independent samples. ${ }^{*} P<0.05$ by Student's $t$-test. WT, wild type.

Tissue cultures of mesenteric fat indicated strong chemokine and cytokine responses in intestinal inflammation; e.g., production of the MCP-1 was significantly upregulated in colitic mice. ${ }^{9}$ In our work, fat tissue of diseased mice or LPS-stimulated fat tissue of healthy mice released substantial amounts of this chemokine, suggesting that bacterial products induce MCP-1 expression by resident cells preceding the before mentioned infiltration of macrophages. The upregulated expression of IL-10 in fat tissue of colitic mice could represent another anti-inflammatory pathway. In addition, similar to the creeping fat of patients with Crohn's disease, ${ }^{36}$ the adipokine leptin is upregulated in mesenteric fat tissue of mice suffering from chronic intestinal inflammation. 

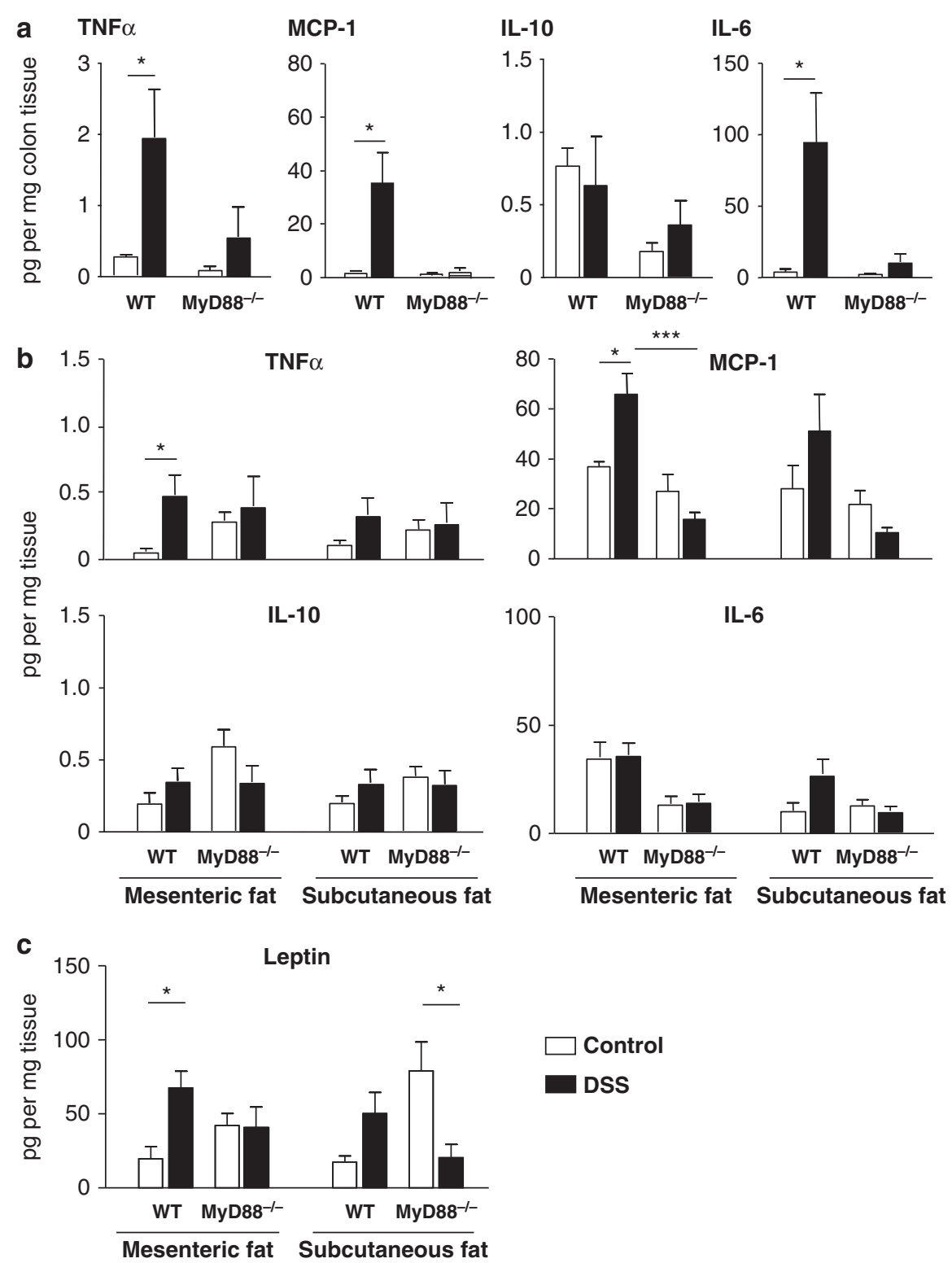

Figure 8 Cytokine response of the colon and fat tissue in the absence of MyD88 signaling. Chronic colitis was induced in WT and MyD88 ${ }^{-/-}$ mice. (a) Cytokine production was assessed by CBA from the supernatants of whole-tissue cultures of colon and (b) of fat tissue samples. (c) Leptin production in the supernatant of fat tissue samples was determined by ELISA. Mean values \pm s.e.m. of $6-10$ mice per group. ${ }^{\star} P<0.05,{ }^{\star \star} P<0.01$, and ${ }^{* \star *} P<0.005$ by Student's $t$-test. CBA, Cytometric Bead Array; ELISA, enzyme-linked immunosorbent assay; WT, wild type.

Although leptin exerts a pro-inflammatory role in models of intestinal inflammation, ${ }^{20-22}$ it is prerequisite for appropriate T-cell and innate immune responses. ${ }^{37,38}$ Thus, changes in the local levels of these cytokines might be essential for efficient blockage of bacterial translocation. But what might orchestrate cytokine production in adipose tissue?

Adipocytes and preadipocytes express functional innate receptors including TLR and nucleotide oligomerization domain. ${ }^{1-13,39}$ Indeed, in vitro stimulation of tissue samples with the TLR-ligand LPS favored increased production of cytokines that are equally upregulated in the mesenteric fat of colitic mice. This altered cytokine response present in mesenteric fat of colitic mice even in the absence of live bacteria is most likely induced by bacterial products. And the absence of living bacteria could be the evidence that the anti-bacterial activity within the mesenteric fat is efficient.

To further explore the role of innate stimulation in bacterial translocation MyD88 ${ }^{-1-}$ mice were used in the studies. For these a high susceptibility to bacterial translocation had already been reported..$^{18}$ Indeed, only in MyD $88^{-1-}$ mice, bacterial translocation to mesenteric fat and further tissues occurred even in health.

In our experiments, MyD88 ${ }^{-/-}$but not WT mice died as a consequence of DSS treatment. The protective role of TLRdependent signaling for colonic repair might be one reason for the increased mortality. ${ }^{40}$ MyD88 deficiency has also been associated with a decreased host defense against Citrobacter rodentium partially mediated by an impaired epithelial integrity. ${ }^{41,42}$ 
Our analysis of the epithelial barrier revealed that differences between WT and MyD88 ${ }^{-1-}$ tissues concerning flux rates and epithelial resistance were dependent on diverse epithelial structure and not attributed to impaired epithelial integrity in MyD88 ${ }^{-1-}$ mice.

As for the cytokine response of the intestinal wall as well as of the mesenteric fat tissue in diseased and healthy MyD88 ${ }^{-/-}$ mice, there was no significant increase of any mediator produced in either colon or fat tissue cultures when comparing healthy and colitic mice. Thus, increased cytokine production within the adipose tissue in intestinal inflammation depends on intact innate receptor responses. This is of particular interest as mutations in a variety of genes including nucleotide oligomerization domain 2 and ATG16L1 that are involved in innate immune responses including uptake and processing of bacteria as well as cytokine production confer an increased susceptibility to Crohn's disease. $^{14,43}$ It is tempting to speculate that our experimental model of DSS colitis in MyD88 ${ }^{-1-}$ mice mimics impaired immunity in Crohn's disease patients and that in these individuals similarly live bacteria are more common in mesenteric adipose tissue due to impaired local immune response.

But why are live bacteria so rarely present in adipose tissue even in colitic WT mice? Cytokine production following contact with bacterial products is not the sole mechanism of defence cells from adipose tissue. The preadipocyte cell line 3T3L1 had already been described to phagocyte yeast cells. ${ }^{17}$ We extend this by testing the phagocytic activity of primary preadipocytes as compared with bone marrow-derived dendritic cells and macrophages. Our preadipocytes proved to be as efficient phagocytes as these professional phagocytes and ingested a broad range of antigens. It is tempting to conclude that in vivo similar effects occur in the mesenteric fat, i.e., translocating bacteria are not only confronted with increased cytokine levels, but also resident cells of the fat might already phagocyte these bacteria and thus prevent the body from their further dissemination. However, owing to the lack of MHCII expression on preadipocytes, they do not serve as APCs.

In summary, our data provide evidence that the mesenteric fat tissue protects the host from systemic bacterial distribution after translocation from the intestine. Phagocytosis by the fat cells is one mode of action to prevent bacterial translocation. In addition, translocalizing bacteria and bacterial fragments stimulate production of leptin, IL-10, and MCP-1. These mediators not only help to control the adjacent intestinal inflammation, but also facilitate infiltration of immune cells into the mesenteric fat tissue allowing for a successful defense. At this point one cannot exclude an additional pro-inflammatory effect of the mesenteric fat thus enhancing intestinal inflammation. Recent reports of mesenteric fat being a major source of C-reactive protein with production possibly linked to increased bacterial translocation in Crohn's disease patients, as well as the increased expression of anti-inflammatory genes at this site further support the hypothesis that mesenteric fat has an active role in both, the control of bacterial translocation and nearby inflammation. ${ }^{44-46}$ Thus, the mesenteric adipose tissue can be considered as a second barrier that is, similar to the epithelial barrier, strongly regulated by the innate immune system. As a consequence the hypertrophy of the mesenteric fat in Crohn's disease could represent a defense mechanism to protect the body from infiltrating bacteria.

\section{METHODS}

Mice. Six- to eight-week-old female WT C57Bl/6 and C57Bl/Ks mice, and $\mathrm{MyD} 88^{-1-}$ mice on the $\mathrm{C} 57 \mathrm{Bl} / 6 \mathrm{~J}$ background were obtained from Harlan Winkelmann (Borchen, Germany) or bred at the Institutes for Experimental Medicine (Charité, Berlin, Germany). Animal protocols were approved by the Regional Animal Study Committee.

Acute and chronic DSS-induced colitis, clinical assessment, and histological scoring. Acute colitis was induced by feeding 4\% DSS (molecular weight $40 \mathrm{kDa}$; MP Biomedicals, Illkirch, France) dissolved in sterile, distilled water ad libitum from day 1 to 8 , followed by 1 day of regular drinking water. For chronic DSS colitis, mice were exposed to threefive cycles consisting of 6 days of 3\% DSS followed by 6-day intervals of distilled water. Clinical assessment of colitis and histological scoring of excised coli were assessed as described previously. ${ }^{20}$ In brief, body weight, rectal bleeding, and stool consistency were determined daily. Weight changes were calculated in relation to the weight at baseline (100\%). Stool consistency was scored as follows: 0 , well-formed pellets; 2 , pasty and semi-formed stools; and 4, liquid stools. Rectal bleeding was scored as follows: 0, no blood using hemoccult (Hemocare; Care Diagnostica, Voerde, Germany); 2, positive hemoccult; and 4, gross bleeding. Colon length was measured at the end of experiment. Postmortem of 4-6 colon segments were fixed in buffered formalin (4\%; Sigma Aldrich, Taufkirchen, Germany) for evaluation of DSS colitis by hematoxylin/eosin staining. Histological signs of inflammation were assessed as a combined score of inflammatory cell infiltration (0-3) and tissue damage (0-3). In the resulting score ranging from 0 to 6,0 represented no signs of inflammation and 6 maximum disease damage.

Assessment of FOva presentation by MHCII. FOva presentation by MHCII was performed as described previously. ${ }^{24,47}$ Briefly, modified ovalbumin peptides 323-339 (iSQAVHAAHAEINEAGRc; Institute for Biochemistry, Charité, Berlin, Germany) was labeled using a 10-fold molar excess of fluorescein isothiocyanate isomer 1 (FITC, Sigma Aldrich). Unconjugated FITC was removed and the buffer exchanged for phosphatebuffered saline (PBS) by gel filtration (Sephadex G10; GE Healthcare, Freiburg, Germany). Flow cytometric detection of FOva was assessed using magnetofluorescent liposomes (Cy5) generated and conjugated to sheepanti-Dig (Fab fragments; Roche, Roche Deutschland Holding GmbH, Grenzach - Whylen, Germany). FOva (1 mg) was administered orally, control mice received PBS only. After $3 \mathrm{~h}$, cells from the spleen, mesenteric lymph nodes, Peyer's patches, and mesenteric fat were isolated and washed twice with PBS with $0.1 \%$ bovine serum albumin (PAA Laboratories, Marburg, Germany). Single-cell suspensions were incubated with anti-Fc receptor antibody $\left(20 \mathrm{\mu g} \mathrm{ml}^{-1}\right.$; Deutsches Rheuma-Forschungszentrum Berlin), Beriglobin ( $4 \mathrm{mg} \mathrm{ml}^{-1}$; CSL Behring, Marburg, Germany), and rat immunoglobulin ( $0.1 \mathrm{mg} \mathrm{ml}^{-1}$; Jackson ImmunoResearch, Suffolk, UK) for $30 \mathrm{~min}$. Next, surface antigens (MHCII-PeCy7; 1:500; eBioscience, Frankfurt, Germany) were labeled. After washing, digoxigenin-labeled anti-FITC antibodies (1:1,000; a kind gift from Miltenyi Biotec, Bergisch Gladbach, Germany) were added and cells incubated for $10 \mathrm{~min}$ on ice. After washing, cells were incubated for $10 \mathrm{~min}$ on ice with the antidigoxigenin anti-biotin complex (1:2,000; a kind gift from Miltenyi Biotec). Next, biotinylated Cy5-labeled magnetofluorescent liposomes were added (1:200) for $45 \mathrm{~min}$ on ice. Samples were washed, and characterized by flow cytometric analysis using a FACSCantoII and the FacsDiva software (BD Biosciences, Heidelberg, Germany). Propidium iodide staining and scatter properties were used to exclude dead cells.

Preparation of preadipocytes. Mesenteric fat tissue from C57Bl/6 mice was excised, minced, and washed in Hanks's balanced salt 
solution (PAA Laboratories). Tissue was incubated in digestion medium consisting of Hanks's balanced salt solution supplemented with collagenase II $\left(1.5 \mathrm{mg} \mathrm{ml}^{-1}\right)$, bovine serum albumin, (3.5\%) and glucose $\left(550 \mu \mathrm{moll}^{-1}\right)$ at $37^{\circ} \mathrm{C}$ for $25 \mathrm{~min}$, mashed through a $100-\mu \mathrm{m}$ nylon net (BD Biosciences) and centrifuged at $200 \mathrm{~g}$ for $10 \mathrm{~min}$. Pelleted cells were washed twice in a culture medium consisting of Dulbecco's modified Eagle's medium/HAMS F-12 medium (PAA Laboratories) supplemented $10 \%$ fetal calf serum (Linaris, Bettingen, Germany), penicillin $\left(100 \mathrm{U} \mathrm{ml}^{-1}\right)$, and streptomycin $\left(100 \mu \mathrm{g} \mathrm{ml}^{-1}\right)$ and seeded into 48 -well plates $\left(5 \times 10^{5}\right.$ cells per well). The following day non-adherent cells were discarded, and adherent cells were propagated. Lineage commitment of the cells was confirmed by conversion to adipocytes in the presence of insulin (Aventis Pharma, Frankfurt, Germany) and hydrocortisone (Pharmacia, Karlsruhe, Germany) as described previously. ${ }^{12}$

Bone marrow-derived dendritic cells and macrophages. To obtain dendritic cells or macrophages, bone marrow was flushed from bones of C57Bl/6 mice using Dulbecco's modified Eagle's medium/HAMS-F12 with $10 \%$ fetal calf serum (Linaris). Cells were washed twice and seeded in a culture medium supplemented with granulocyte macrophagecolony stimulation factor or macrophage-colony stimulating factor (20 $\mathrm{n} \mathrm{ml}^{-1}$; PeproTech, Hamburg, Germany) to induce maturation to either dendritic cells or macrophages. Non-adherent cells were cultured for 6 days and every other day half of the medium supplemented with the respective cytokines was replaced.

Immunohistochemistry. After heat-induced epitope retrieval, $2-\mu \mathrm{m}$ sections of formalin-fixed tissue were blocked with avidin/biotin (Dako, Hamburg, Germany) and incubated with polyclonal rabbit anti-human CD3 antibody (1:20; Dako), rat anti-mouse F4/80 antibody (1:50; eBioscience, San Diego, CA) or isotype control antibodies (Dianova, Hamburg, Germany) followed by biotinylated secondary antibodies (1:200; Invitrogen, Carlsbad, CA). For detection, the REAL Detection System with alkaline phosphatase/RED (Dako) was applied, and nuclei were counterstained with hematoxylin. Images were acquired using an AxioImager Z1 microscope (Carl Zeiss MicroImaging, Oberkochen, Germany). Positive cells were quantified and averaged from three high power fields $\left(3 \times 0.237 \mathrm{~mm}^{2}\right)$.

Flow cytometric characterization of adipose tissue cells. Cell suspensions of mesenteric or splenic adipose tissue were washed twice in fluorescence-activated cell sorting buffer consisting of PBS with $0.5 \%$. bovine serum albumin. The following fluorochrome-coupled anti-mouse antibodies were applied: CD3-allophycocyanine (APCs), CD4-FITC, CD8 $\alpha$ phycoerythrin (PE), CD11b-PE, CD11c-indocyanine 7 (Cy7), CD25-PE, CD69-Cy7, CD86-FITC, F4/80-PE, MHCII-APCs, and NK1.1-PE (all obtained from eBiosciences), MOMA-2-FITC (Serotec, Düsseldorf, Germany) and $\alpha \beta T C R-A P C s$ (Caltag Laboratories, Hamburg, Germany). To exclude dead cells, propidium iodide staining was performed and cells were characterized by flow cytometry using a FACSCantoII and the FacsDiva software (BD Biosciences).

Phagocytosis assay. Bone marrow-derived dendritic cells and macrophages as well as preadipocytes were washed twice and adjusted to $1 \times 10^{6}$ cells per ml. Cell suspensions $(500 \mu \mathrm{l})$ were mixed with APClabeled ovalbumin (100 particles per cell), FITC-labeled latex beads (50 particles per cell), or FITC-labeled opsonized or non-opsonized Staphylococcus aureus (100 particles per cell; all obtained from Molecular Probes, Karlsruhe, Germany). Cells incubated under gentle shaking at $37^{\circ} \mathrm{C}$ for $60 \mathrm{~min}$ or, as negative control, on ice, were subsequently washed three times with ice-cold fluorescence-activated cell sorting buffer and analyzed by flow cytometry. To determine phagocytic activity, the percentage of fluorescent cells in the negative control was subtracted from the percentage in the samples incubated at $37^{\circ} \mathrm{C}$.

Cultural analyses for detection of live bacteria. Luminal contents from the colon were resuspended in PBS, weighed, and $100 \mu$ laliquots of serial dilutions plated onto solid medium (Oxoid, Wesel, Germany). Bacteria were grown at $37^{\circ} \mathrm{C}$ for 2 days under aerobic or for 4 days under anaerobic conditions, and total numbers were determined by colony counting on Columbia blood agar (Merck, Darmstadt, Germany). Bile esculin, McConkey, Rogosa medium, and Columbia blood agar supplemented with haemin, kanamycin, and vancomycin (Merck) were used for quantitative identification of Enterococci, Enterobacteria, lactic acid bacteria (mainly Lactobacillus), and Bacteroides/Prevotella spp., respectively. The amounts of Gram-negative and Gram-positive bacteria were determined by counting of distinct colony morphotypes on Columbia blood agar. Bacteria were subcultivated and further investigated by Gram staining and by biochemical analysis with the API20E, API50CH, and API-Rapid-ID32A systems (BioMérieux, Nürtingen, Germany). Results were expressed as colony forming unit per g luminal colon content. Blood and tissue samples removed under sterile conditions were cultured in brain heart infusion and thioglycolate broths (Oxoid) for at least 1 week at $37^{\circ} \mathrm{C}$, and bacterial growth was monitored by turbidity. Aliquots from turbid broths were cultivated on solid media under aerobic and anaerobic conditions, and the bacteria were identified microbiologically and biochemically as described above.

Cytokine detection in tissue culture supernatants. Colons cut open were washed with PBS and strips of $1 \mathrm{~cm}^{2}$ were placed in RPMI 1640 with penicillin $\left(100 \mathrm{U} \mathrm{ml}^{-1}\right)$ and streptomycin $\left(100 \mu \mathrm{g} \mathrm{ml}^{-1}\right.$; PAA Laboratories). Fat tissue was cut into strips, weighed, washed, and cultured in a medium in 24-well plates. After $24 \mathrm{~h}$ at $37^{\circ} \mathrm{C}$, culture supernatants were tested for IL-6, IL-10, IL-12p70, IFN $\gamma$, tumor necrosis factor- $\alpha$, and MCP-1 by the Mouse Inflammation Cytometric Bead Array (BD Biosciences). In subsets of samples specific enzyme-linked immunosorbent assays were applied to determine IL-6 (BD Biosciences) and leptin (R\&D Systems, Wiesbaden, Germany) according to the manufacturer's protocols.

Characterizing of the epithelial barrier. Colon specimens were mounted in a miniaturized Ussing chamber (exposed area $0.049 \mathrm{~cm}^{2}$ ) as described previously. ${ }^{48}$ To differentiate the epithelial and subepithelial portion of transmural resistance, impedance analysis was performed. ${ }^{49}$ Briefly, 48 discrete frequencies of an effective sine wave alternating current of $35 \mathrm{~mA} \mathrm{~cm}^{-2}$, ranging from 1.3 to $65 \mathrm{kHz}$, were applied and changes in tissue voltage detected by phase-sensitive amplifiers ( 1,250 frequency response analyzer and 1,286 electrochemical interface; Solartron Schlumberger, Farnborough, Hampshire, UK). Complex impedance values were calculated and corrected for the resistance of the bathing solution and the frequency behavior of the measuring device. The impedance loci were plotted in Nyquist diagrams fitted by least squares analysis. Transmural wall resistance $\left(R^{\mathrm{t}}\right)$ was obtained at low, and subepithelial resistance $\left(R^{s}\right)$ at high frequencies. Epithelial resistance $\left(R^{\mathrm{e}}\right)$ equals $R^{\mathrm{t}}-R^{\mathrm{s}}$ paracellular permeability was determined by mannitol flux (mucosal-to-serosal). ${ }^{48}$ Briefly, $10^{7}$ c.p.m. $\left[{ }^{3} \mathrm{H}\right]$ mannitol (specific activity $20 \mathrm{Ci} \mathrm{mmol}^{-1}$; ARC, St Louis, MO) was added to the mucosal side. After an equilibration period, a fraction of the serosal volume was sampled over three $15 \mathrm{~min}$ intervals and analyzed using a $\beta$-counter.

Surface area of the colon mucosa. The surface area of the colon mucosa was assessed as the ratio of mucosal-to-serosal surface area from the lengths of apical epithelial as well as muscularis mucosae linings in equivalent fields of view of adjacent sections. Crypt height and density were determined from five sections per mouse, each $\sim 700 \mu \mathrm{m}$ in width. Hematoxylin/eosin-stained colon sections were analyzed using the freehand line selection tool of Image J (Rasband, ImageJ, NIH, Bethesda, MD; http://rsb.info.nih.gov/ij/, 1997-2009).

Statistics. Significance was determined using the GraphPad PRISM software (Version 4.00. for Windows; GraphPad Software, San Diego, CA).

SUPPLEMENTARY MATERIAL is linked to the online version of the paper at http://www.nature.com/mi 


\section{ACKNOWLEDGMENTS}

The study was supported by the Deutsche Forschungsgemeinschaft, Sonderforschungsbereich 633 "Induction and Modulation of T Cell Mediated Immune Responses in the Gastrointestinal Tract", and SI-749/6-1 (to BS).

\section{DISCLOSURE}

A Scheffold is employed by Miltenyi Biotec. The rest of the authors they declare no conflict of interest.

(C) 2012 Society for Mucosal Immunology

\section{REFERENCES}

1. Sheehan, A.L., Warren, B.F., Gear, M.W. \& Shepherd, N.A. Fat-wrapping in Crohn's disease: pathological basis and relevance to surgical practice. Br. J. Surg. 79, 955-958 (1992).

2. Laffineur, G. et al. (Bacterial translocation in Crohn disease). Gastroenterol. Clin. Biol. 16, 777-781 (1992).

3. Gay, J. et al. Mesenteric adipose tissue is colonized by bacterial flora and expresses pathogen recognition receptors in Crohn's disease. Gastroenterology 128(Suppl 2), A503 (2005).

4. Fantuzzi, G. \& Faggioni, R. Leptin in the regulation of immunity, inflammation, and hematopoiesis. J. Leukoc. Biol. 68, 437-446 (2000).

5. Coppack, S.W. Pro-inflammatory cytokines and adipose tissue. Proc. Nutr. Soc. 60, 349-356 (2001).

6. Yu, R., Park, J.S., Kawada, T. \& Kwon, B.S. Alteration of a macrophages inflammatory protein-related protein-2 (MRP-2) response by high fat and cholesterol diet in mice. Life Sci. 70, 2535-2545 (2002).

7. Kishimoto, T. Interleukin-6: discovery of a pleiotropic cytokine. Arthritis Res. Ther. 8, S2 (2006)

8. Fontana, L., Eagon, J.C., Trujillo, M.E., Scherer, P.E. \& Klein, S. Visceral fat adipokine secretion is associated with systemic inflammation in obese humans. Diabetes 56, 1010-1013 (2007).

9. Deshmane, S.L., Kremlev, S., Amini, S. \& Sawaya, B.E. Monocyte chemoattractant protein-1 (MCP-1): an overview. J. Interferon Cytokine Res. 29, 313-326 (2009).

10. Paul, G. et al. Profiling adipocytokine secretion from creeping fat in Crohn's disease. Inflamm. Bowel Dis. 12, 471-477 (2006).

11. Lin, Y. et al. The lipopolysaccharide-activated toll-like receptor (TLR)-4 induces synthesis of the closely related receptor TLR-2 in adipocytes. J. Biol. Chem. 275, 24255-24263 (2000).

12. Batra, A. et al. Leptin-dependent toll-like receptor expression and responsiveness in preadipocytes and adipocytes. Am. J. Pathol. 170, 1931-1941 (2007)

13. Stroh, T. et al. Nucleotide oligomerization domains 1 and 2: regulation of expression and function in preadipocytes. J. Immunol. 181, 3620-3627 (2008).

14. Plantinga, T.S. et al. Crohn's disease-associated ATG16L1 polymorphism modulates pro-inflammatory cytokine responses selectively upon activation of NOD2. Gut 60, 1229-1235 (2011).

15. Kawai, T., Adachi, O., Ogawa, T., Takeda, K. \& Akira, S. Unresponsiveness of MyD88-deficient mice to endotoxin. Immunity 11, 115-122 (1999).

16. Heimesaat, M.M. et al. Shift towards pro-inflammatory intestinal bacteria aggravates acute murine colitis via Toll-like receptors 2 and 4. PLoS One 2, e662 (2007)

17. Charriere, G. et al. Preadipocyte conversion to macrophage. Evidence of plasticity. J. Biol. Chem. 278, 9850-9855 (2003).

18. Rakoff-Nahoum, S., Paglino, J., Eslami-Varzaneh, F., Edberg, S. \& Medzhitov, R. Recognition of commensal microflora by toll-like receptors is required for intestinal homeostasis. Cell 118, 229-241 (2004).

19. Vaishnava, S., Behrendt, C.L., Ismail, A.S., Eckmann, L. \& Hooper, L.V. Paneth cells directly sense gut commensals and maintain homeostasis at the intestinal host-microbial interface. Proc. Natl. Acad. Sci. USA 105, 20858-20863 (2008).

20. Siegmund, B., Lehr, H.A. \& Fantuzzi, G. Leptin: a pivotal mediator of intestinal inflammation in mice. Gastroenterology 122, 2011-2025 (2002).

21. Fantuzzi, G. et al. Defining the role of T cell-derived leptin in the modulation of hepatic or intestinal inflammation in mice. Clin. Exp. Immunol. 142, 31-38 (2005).

22. Siegmund, B. et al. Leptin receptor expression on T lymphocytes modulates chronic intestinal inflammation in mice. Gut 53, 965-972 (2004).

23. Ziv, E. \& Bendayan, M. Intestinal absorption of peptides through the enterocytes. Microsc. Res. Tech. 49, 346-352 (2000).
24. Kunkel, D., Kirchhoff, D., Volkmer-Engert, R., Radbruch, A. \& Scheffold, A. Sensitive visualization of peptide presentation in vitro and ex vivo. Cytometry A 54, 19-26 (2003).

25. Kunkel, D., Kirchhoff, D., Nishikawa, S., Radbruch, A. \& Scheffold, A. Visualization of peptide presentation following oral application of antigen in normal and Peyer's patches-deficient mice. Eur. J. Immunol. 33, 1292-1301 (2003)

26. Duchmann, R. et al. Tolerance exists towards resident intestinal flora but is broken in active inflammatory bowel disease (IBD). Clin. Exp. Immunol. 102, 448-455 (1995)

27. Macpherson, A., Khoo, U.Y., Forgacs, I., Philpott-Howard, J. \& Bjarnason, I. Mucosal antibodies in inflammatory bowel disease are directed against intestinal bacteria. Gut 38, 365-375 (1996).

28. Schulzke, J.D. et al. Epithelial tight junctions in intestinal inflammation. Ann. NY Acad. Sci. 1165, 294-300 (2009).

29. Darfeuille-Michaud, A. et al. High prevalence of adherent-invasive Escherichia coli associated with ileal mucosa in Crohn's disease. Gastroenterology 127, 412-421 (2004).

30. Martin, H.M. et al. Enhanced Escherichia coli adherence and invasion in Crohn's disease and colon cancer. Gastroenterology 127, 80-93 (2004).

31. Kosiewicz, M.M. et al. Th1-type responses mediate spontaneous ileitis in a novel murine model of Crohn's disease. J. Clin. Invest. 107, 695-702 (2001).

32. Olson, T.S. et al. The primary defect in experimental ileitis originates from a nonhematopoietic source. J. Exp. Med. 203, 541-552 (2006).

33. Suenaert, P. et al. Effects of T cell-induced colonic inflammation on epithelial barrier function. Inflamm. Bowel Dis. 16, 1322-1331 (2010).

34. Olefsky, J.M. \& Glass, C.K. Macrophages, inflammation, and insulin resistance. Annu. Rev. Physiol. 72, 219-246 (2010).

35. Weisberg, S.P. et al. Obesity is associated with macrophage accumulation in adipose tissue. J. Clin. Invest. 112, 1796-1808 (2003).

36. Barbier, M. et al. Overexpression of leptin mRNA in mesenteric adipose tissue in inflammatory bowel diseases. Gastroenterol. Clin. Biol. 27, 987-991 (2003).

37. Lord, G.M. et al. Leptin modulates the T-cell immune response and reverses starvation-induced immunosuppression. Nature 394, 897-901 (1998).

38. Rodriguez, L., Graniel, J. \& Ortiz, R. Effect of leptin on activation and cytokine synthesis in peripheral blood lymphocytes of malnourished infected children. Clin. Exp. Immunol. 148, 478-485 (2007).

39. Poulain-Godefroy, O. et al. Inflammatory role of Toll-like receptors in human and murine adipose tissue. Mediators Inflamm. 2010, 823486 (2010).

40. Zheng, L., Riehl, T.E. \& Stenson, W.F. Regulation of colonic epithelial repair in mice by Toll-like receptors and hyaluronic acid. Gastroenterology 137, 2041-2051 (2009)

41. Cario, E., Gerken, G. \& Podolsky, D.K. Toll-like receptor 2 controls mucosal inflammation by regulating epithelial barrier function. Gastroenterology 132, 1359-1374 (2007)

42. Gibson, D.L. et al. MyD88 signalling plays a critical role in host defence by controlling pathogen burden and promoting epithelial cell homeostasis during Citrobacter rodentium-induced colitis. Cell Microbiol. 10, 618-631 (2008).

43. Ramjeet, M., Hussey, S., Philpott, D.J. \& Travassos, L.H. 'Nodophagy': new crossroads in Crohn disease pathogenesis. Gut Microbes 1, 307-315 (2010).

44. Zulian, A. et al. Visceral adipocytes: old actors in obesity and new protagonists in Crohn's disease? Gut 61, 86-94 (2012).

45. Siegmund, B. Mesenteric fat in Crohn's disease: the hot spot of inflammation? Gut 61, 3-5 (2012).

46. Peyrin-Biroulet, L. et al. Mesenteric fat as a source of $C$ reactive protein and as a target for bacterial translocation in Crohn's disease. Gut 61, 78-85 (2012).

47. Scheffold, A., Assenmacher, M., Reiners-Schramm, L., Lauster, R. \& Radbruch, A. High-sensitivity immunofluorescence for detection of the pro- and anti-inflammatory cytokines gamma interferon and interleukin-10 on the surface of cytokine-secreting cells. Nat. Med. 6 $107-110$ (2000).

48. Stockmann, M. et al. Duodenal biopsies of HIV-infected patients with diarrhoea exhibit epithelial barrier defects but no active secretion. Aids 12 43-51 (1998)

49. Fromm, M. et al. High-resolution analysis of barrier function. Ann. NY Acad. Sci. 1165, 74-81 (2009). 